\title{
Vulnerability to depression: what is the role of stress genes in gene $x$ environment interaction?
}

\author{
W. El Hage $\mathrm{e}^{1,2 *}$, J. F. Powell ${ }^{2}$ and S. A. Surguladze ${ }^{2}$ \\ ${ }^{1}$ INSERM U930 ERL CNRS 3106, CHRU de Tours, Université François Rabelais, Tours, France \\ ${ }^{2}$ Institute of Psychiatry, King's College London, UK
}

\begin{abstract}
Vulnerability to depression has been linked to the interaction of genetic predisposition with stressful life events. This review considers the associations between serotonergic and hypothalamic-pituitary-adrenal (HPA) systems. We follow the standpoint of a previous Editorial Review (Bhagwagar \& Cowen, Psychological Medicine 2008, 38, 307-313) and consider another possible mechanism of vulnerability to depressive disorder, that is we suggest that the gene $\times$ environment interaction involves complex participation of serotonergic genes modulating response to stress through the HPA system.
\end{abstract}

Received 20 May 2008; Revised 12 December 2008; Accepted 19 December 2008; First published online 12 February 2009

Key words: HPA axis, serotonin, depression, genes.

\section{Introduction}

Major depressive disorder (MDD) has a heterogeneous aetiology and the contribution of environmental factors is at least equivalent to that of genetic factors. A genetic diathesis predisposes individuals to the disorder in the context of life stressors (Kendler et al. 2001). Environmental factors are now taken into account in studies of MDD, which is not a trivial task because their evaluation is usually retrospective. Moreover, it is not explicit which stressful events are the most relevant, ranging from acute to chronic or traumatic stress events. The evidence suggests that the acute and recent stress is more relevant, compared with chronic and distal events (for a review see Monroe \& Reid, 2008).

In the following sections we consider some of the possible factors that play a role in the geneenvironment interaction relevant to the concept of vulnerability to MDD.

\section{The serotonergic system}

Serotonergic vulnerability (Jans et al. 2006) is an increased sensitivity to natural or experimental alterations of the serotonergic system, such as genetic factors, female gender, personality characteristics (neuroticism), environmental stress (prenatal stress, life experiences) or drug use. An insertion/deletion

\footnotetext{
* Address for correspondence: Dr W. El Hage, Psychological Medicine and Psychiatry, Institute of Psychiatry, King's College London, London SE5 8AF, UK.

(Email: Wissam.El-Hage@iop.kcl.ac.uk)
}

polymorphism in the serotonin transporter-linked promoter region 5-HTTLPR modulates serotonin transporter gene (SLC6A4) expression, where the short allele $(S)$ is associated with lower expression levels compared to the long allele (L). Importantly, the risk for depression has been associated with an interaction of the $S$ allele with stressful life events (Caspi et al. 2003). What are the neural mechanisms of such an interaction? Neuroimaging studies show that, in response to aversive visual signals, $\mathrm{S}$ allele carriers demonstrate amygdala hyperactivity and also altered connectivity between the pregenual anterior cingulate cortex (ACC) and the amygdala (for a meta-analysis see Munafo et al. 2008). In other words, people who genetically have low activity of 5-HTTLPR, and consequently are at risk for developing depression, demonstrate an overactivity of the amygdala to aversive signals. These experiments are regarded as modelling the brain's responsivity to potentially stressful environmental signals. A functional magnetic resonance imaging (fMRI) study (Canli et al. 2006) has indeed found that the life stress measure correlated positively with resting activation in the amygdala and hippocampus in $\mathrm{S}$ allele carriers and negatively in L allele carriers.

The literature indicating a net inhibitory effect of serotonin on amygdala activity (Stutzmann \& LeDoux, 1999) seems to support this model. However, the bigger picture of major depression is far from clear. Thus, a recent meta-analysis has not confirmed a direct link between 5-HTTLPR and MDD (Kato, 2007). Levinson (2006) suggested that there were small positive associations between 5-HTTLPR and depressionrelated personality traits but not with MDD itself. Kato 
(2007) argued that, in depression, the previously reported positive findings of a gene-environmental interaction between 5-HTTLPR and stress were not replicated consistently. One reason for these discrepancies is that 5-HTTLPR polymorphisms are now found to be more complex than previously thought, with at least 14 alleles of the 5-HTTLPR. There are views that the 5-HTTLPR polymorphisms may not be directly associated with MDD but modulate the serotonergic response to stress (for a methodological review see Uher \& McGuffin, 2007).

\section{Stress and the hypothalamic-pituitary-adrenal (HPA) axis}

Traditionally, studies of vulnerability to stress have focused on malfunctioning of the HPA system involving neuroendocrine metabolism. A large body of knowledge suggests that exposure to stress leads to hyperactivation of the HPA system, which, in people with a deficitary feedback mechanism, is followed by hypercortisolism. This hypercortisolism is present during depressive episodes, in remitted patients and in those at high risk, for example in children from affected families (Mannie et al. 2007). Importantly, the degree of hypercortisolism has been shown to predict the occurrence of depression in high-risk individuals (Harris et al. 2000; Halligan et al. 2007).

Two receptor subtypes, glucocorticoid and mineralocorticoid receptors (GR and MR respectively), contribute to the regulation of HPA activity. One of the models of depression (Pariante, 2006) suggests that the main neuroendocrinological abnormality is glucocorticoid resistance resulting from decreased GR function or expression in the brain. The hypercortisolism would be a compensatory mechanism aiming to overcome the glucocorticoid resistance. Thus, in a proportion of MDD patients, GR dysfunction might be the primary source of the HPA axis abnormalities. An elevated waking cortisol level might be part of an endophenotype predisposing a subject to the development of depression in the context of stressful life events.

\section{HPA-related genes}

Growing evidence is suggesting that some polymorphisms in the MR and GR genes may underlie vulnerability to depression.

\section{Glucocorticoid receptor}

A significant association of MDD with polymorphisms in the gene coding for the GR was observed in a Belgian sample (in the promoter region NR3C1-1, rs10482605), a Swedish sample (R23K, rs6190) and a German population (R23K) (van West et al. 2005; van Rossum et al. 2006). Kumsta et al. (2007) investigated 206 healthy subjects and associations between common GR gene (NR3C1) polymorphisms and HPA axis responses to psychosocial stress, using the Trier Social Stress Test (TSST). The study detected a significant association, but no clear aetiological relationship, between GR gene polymorphisms (ER22/23EK, N363S, BclI, $9 \beta)$ and HPA axis regulation and on glucocorticoid sensitivity as well as a sex-specific impact (BclI GG, $9 \beta$ AG) on responses to psychosocial stress. Recently, Bradley et al. (2008) showed that child abuse interacts with the corticotrophin-releasing factor type 1 receptor (CRF-R1) genotype to enhance risk for depression in adults, in two independent ethnically different populations. They suggested that alterations in CRF-R1 responsiveness during these early emotionally crucial periods could alter later risk for HPA axis overactivity and depression.

In sum, the GR- and CRF-coding genetic polymorphisms are likely to have a modulating (rather than a causal) effect in the development of MDD.

\section{Mineralocorticoid receptor}

In a cohort of healthy males (DeRijk et al. 2006), carriers of the minor allele of the MR gene variant I180V showed significantly higher salivary and total cortisol and also heart rate responses to the TSST than noncarriers. Kuningas et al. (2006) assessed the impact of cortisol levels and of variations in the MR and GR genes on depressive symptoms. They showed that the prevalence of depressive symptoms was dependent on a variation in the MR gene, where carriers of the MR-I180V single nucleotide polymorphism (SNP) had more depressive symptoms compared to the noncarriers.

Thus, several genes involved in modulation of HPA axis functioning may have a role in the mechanisms of vulnerability to MDD. The involvement of serotonergic genes in vulnerability has also been highlighted. The question arises: do these mechanisms of vulnerability operate independently? We believe there should be a common pathway where the serotonergic and HPA systems converge in developing vulnerability to depressive states. The functional links between these systems may provide some clues.

\section{Links between 5-HT and HPA systems}

Gotlib et al. (2008) has shown recently that cortisol response may be a crucial mechanism underlying the association between the 5-HTTLPR gene and exposure 


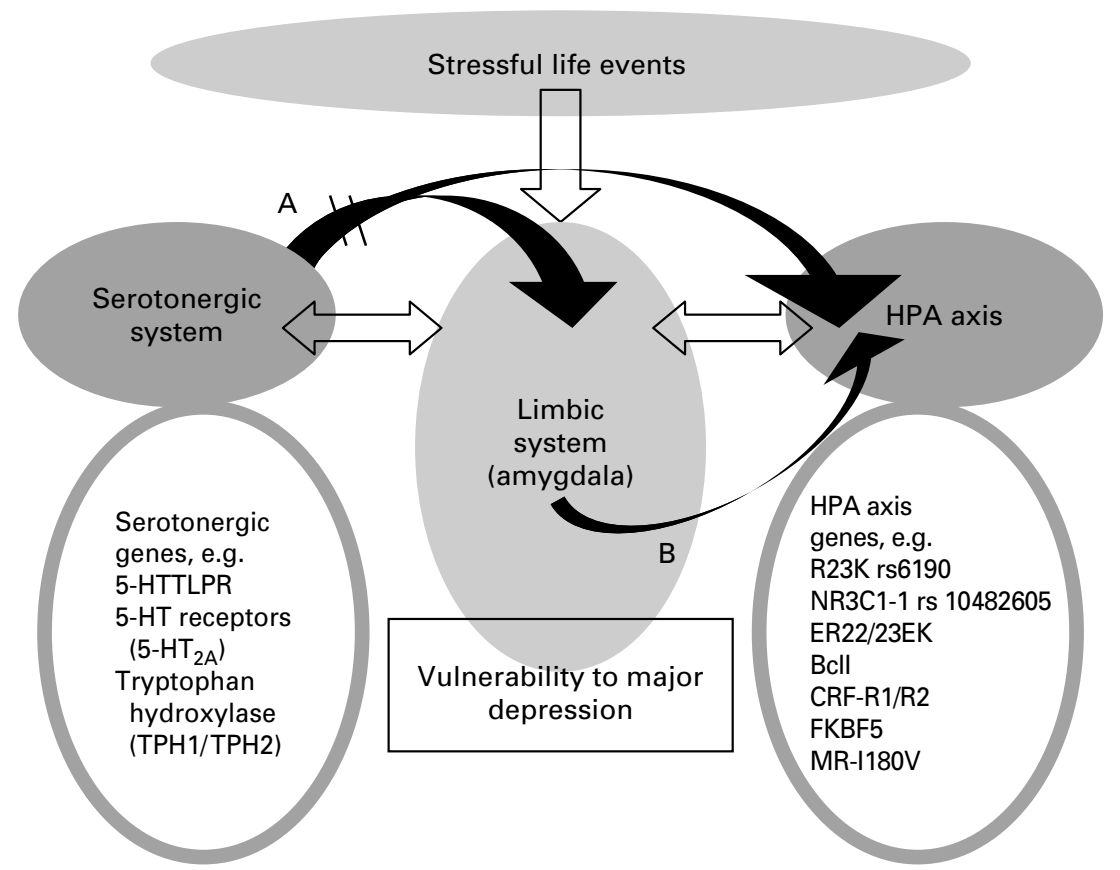

Fig. 1. Altered relationships between serotonergic, limbic and hypothalamic-pituitary-adrenal (HPA) systems underlie the vulnerability to depression. Reduced serotonergic inhibition (arrows A) is associated with overactivity in the amygdala and the HPA system. The overactive amygdala provides an additional boost to cortisol and corticotrophin-releasing factor production (arrow B). Genetic polymorphisms are associated with risk/vulnerability to depression. This diagram demonstrates the relationships between three systems underlying the vulnerability to depression. We acknowledge that there are several other systems involved (e.g. dopaminergic system, lateral, orbital frontal and cingulate circuits) but these are not the subject of this review.

to stressful events in increasing risk for depression. We consider below possible neural processes involved in such an interaction (Fig. 1).

It is well established that the activity of the amygdala is associated with the HPA axis through serotonergic projections to the hypothalamus (Weidenfeld et al. 2002), influencing the stress response (Herman et al. 2005). It has also been suggested that the central amygdaloid nucleus takes part in overproduction of CRF in melancholic patients with hypercortisolaemia (Reul \& Holsboer, 2002).

However, the serotonergic system has been found to modulate HPA axis functioning: for example, studies with 5-HTT knockout mice have shown that one of the functions of the serotonin transporter is to restrain the HPA response to stress (Tjurmina et al. 2004; Murphy \& Lesch, 2008). Jabbi et al. (2007) explored the influence of 5-HTTLPR polymorphisms on HPA axis reactivity using combined dexamethasone and CRF challenge, which is known to induce neuroendocrine states similar to stress-related clinical phenotypes. The study showed higher endocrine response in females homozygous for S allele of 5-HTTLPR which might contribute to the sex-related differences in MDD prevalence. Indeed, the same 5-HTTLPR polymorphisms also interacted with baseline measures of cortisol in determining susceptibility to MDD.

\section{Conclusions}

Given the above-mentioned close relationship between the amygdala, serotonergic transmission and the HPA axis, their concerted participation in limbic response to stress might be expected. This response may develop into an exaggerated reaction in people with low activity of 5-HTTLPR/elevated activity in the amygdala, where the hyperactive amygdala enhances HPA axis functioning; sustained hypercortisolism will follow, contingent on MR and GR gene expression.

Future studies of limbic brain modulation by genetic polymorphisms pertaining to serotonergic and HPA systems may tell us more about vulnerability to MDD.

\section{Acknowledgements}

W.E.H. is currently supported by Servier, the French Association of Biological Psychiatry (AFPB) and Janssen-Cilag. He received a research grant from Lundbeck that is unrelated to the content of this manuscript. 


\section{Declaration of Interest}

None.

\section{References}

Bhagwagar Z, Cowen PJ (2008). 'It's not over when it's over' : persistent neurobiological abnormalities in recovered depressed patients. Psychological Medicine 38, 307-313.

Bradley RG, Binder EB, Epstein MP, Tang Y, Nair HP, Liu W, Gillespie CF, Berg T, Evces M, Newport DJ, Stowe ZN, Heim CM, Nemeroff CB, Schwartz A, Cubells JF, Ressler KJ (2008). Influence of child abuse on adult depression: moderation by the corticotropinreleasing hormone receptor gene. Archives of General Psychiatry 65, 190-200.

Canli T, Qiu M, Omura K, Congdon E, Haas BW, Amin Z (2006). Neural correlates of epigenesis. Proceedings of the National Academy of Sciences of the United States of America 103, 16033-16038.

Caspi A, Sugden K, Moffitt TE, Taylor A, Craig IW, Harrington H, McClay J, Mill J, Martin J, Braithwaite A, Poulton R (2003). Influence of life stress on depression: moderation by a polymorphism in the 5 -HTT gene. Science 301, 386-389.

DeRijk RH, Wust S, Meijer OC, Zennaro MC, Federenko IS, Hellhammer DH, Giacchetti G, Vreugdenhil E, Zitman FG, de Kloet ER (2006). A common polymorphism in the mineralocorticoid receptor modulates stress responsiveness. Journal of Clinical Endocrinology and Metabolism 91, 5083-5089.

Gotlib IH, Joormann J, Minor KL, Hallmayer J (2008). HPA axis reactivity: a mechanism underlying the associations among 5-HTTLPR, stress, and depression. Biological Psychiatry 63, 847-851.

Halligan SL, Herbert J, Goodyer I, Murray L (2007). Disturbances in morning cortisol secretion in association with maternal postnatal depression predict subsequent depressive symptomatology in adolescents. Biological Psychiatry 62, 40-46.

Harris TO, Borsanyi S, Messari S, Stanford K, Brown GW, Cleary SE, Shiers HM, Herbert J (2000). Morning cortisol as a risk factor for subsequent major depressive disorder in adult women. British Journal of Psychiatry 177, 505-510.

Herman JP, Ostrander MM, Mueller NK, Figueiredo H (2005). Limbic system mechanisms of stress regulation: Hypothalamo-pituitary-adrenocortical axis. Progress in Neuro-Psychopharmacology and Biological Psychiatry 29, 1201-1213.

Jabbi M, Korf J, Kema IP, Hartman C, van der Pompe G, Minderaa RB, Ormel J, den Boer JA (2007). Convergent genetic modulation of the endocrine stress response involves polymorphic variations of 5-HTT, COMT and MAOA. Molecular Psychiatry 12, 483-490.

Jans LAW, Riedel WJ, Markus CR, Blokland A (2006). Serotonergic vulnerability and depression: assumptions, experimental evidence and implications. Molecular Psychiatry 12, 522-543.
Kato TADA (2007). Molecular genetics of bipolar disorder and depression. Psychiatry and Clinical Neurosciences 61, 3-19.

Kendler KS, Thornton LM, Gardner CO (2001). Genetic risk, number of previous depressive episodes, and stressful life events in predicting onset of major depression. American Journal of Psychiatry 158, 582-586.

Kumsta R, Entringer S, Koper JW, van Rossum EFC, Hellhammer DH, Wust S (2007). Sex specific associations between common glucocorticoid receptor gene variants and hypothalamus-pituitary-adrenal axis responses to psychosocial stress. Biological Psychiatry 62, 863-869.

Kuningas M, de Rijk RH, Westendorp RGJ, Jolles J, Slagboom PE, van Heemst D (2006). Mental performance in old age dependent on cortisol and genetic variance in the mineralocorticoid and glucocorticoid receptors. Neuropsychopharmacology 32, 1295-1301.

Levinson DF (2006). The genetics of depression: a review. Biological Psychiatry 60, 84-92.

Mannie ZN, Harmer CJ, Cowen PJ (2007). Increased waking salivary cortisol levels in young people at familial risk of depression. American Journal of Psychiatry 164, 617-621.

Monroe SM, Reid MW (2008). Gene-environment interactions in depression research: genetic polymorphisms and life-stress polyprocedures. Psychological Science 19, 947-956.

Munafo MR, Brown SM, Hariri AR (2008). Serotonin transporter (5-HTTLPR) genotype and amygdala activation: a meta-analysis. Biological Psychiatry 63, 852-857.

Murphy DL, Lesch KP (2008). Targeting the murine serotonin transporter: insights into human neurobiology. Nature Reviews Neuroscience 9, 85-96.

Pariante CM (2006). The glucocorticoid receptor: part of the solution or part of the problem? Journal of Psychopharmacology 20, 79-84.

Reul JM, Holsboer F (2002). Corticotropin-releasing factor receptors 1 and 2 in anxiety and depression. Current Opinion in Pharmacology 2, 23-33.

Stutzmann GE, LeDoux JE (1999). GABAergic antagonists block the inhibitory effects of serotonin in the lateral amygdala: a mechanism for modulation of sensory inputs related to fear conditioning. Journal of Neuroscience 19, RC8.

Tjurmina OA, Armando I, Saavedra JM, Li Q, Murphy DL (2004). Life-long serotonin reuptake deficiency results in complex alterations in adrenomedullary responses to stress. Annals of the New York Academy of Sciences 1018, 99-104.

Uher R, McGuffin P (2007). The moderation by the serotonin transporter gene of environmental adversity in the aetiology of mental illness: review and methodological analysis. Molecular Psychiatry 13, 131-146.

van Rossum EFC, Binder EB, Majer M, Koper JW, Ising M, Modell S, Salyakina D, Lamberts SWJ, Holsboer F 
(2006). Polymorphisms of the glucocorticoid receptor gene and major depression. Biological Psychiatry 59, 681-688.

van West D, Van Den Eede F, Del-Favero J, Souery D, Norrback KF, Van Duijn C, Sluijs S, Adolfsson R, Mendlewicz J, Deboutte D, Van Broeckhoven C, Claes S (2005). Glucocorticoid receptor gene-based SNP analysis in patients with recurrent major depression.

Neuropsychopharmacology 31, 620-627.

Weidenfeld J, Newman ME, Itzik A, Gur E, Feldman S (2002). The amygdala regulates the pituitaryadrenocortical response and release of hypothalamic serotonin following electrical stimulation of the dorsal raphe nucleus in the rat. Neuroendocrinology 76, 63-69. 